\title{
Rehabilitative care in a specialist palliative day care centre: A study of patients' perspectives
}

\section{CA Belchamber, MH Gousy}

This qualitative study set out to explore cancer patients' perceptions of a rehabilitative care approach, which they experienced in an independent specialist palliative day care centre. A phenomenological approach was chosen and through semistructured interviews, patients' perceptions of their symptoms, beliefs and attitudes towards their rehabilitative care were explored. The relevance and benefits of the rehabilitative care approach were then identified using quality of life markers established during data analysis.

The main factors uncovered and shown to contribute to the rehabilitation process were: environmental factors; participant interaction; normalization; health-care professional interaction; nutrition; mobilization; and education. However, more research is needed to understand how some of the treatment modalities discussed can help reduce fatigue, pain, dyspnoea and nausea in this group of people. Key words: rehabilitation, cancer, palliative care, day centre, symptom management, physiotherapy Belchamber CA, Gousy MH (2004) Rehabilitative care in a specialist palliative day care centre: A study of patients' perspectives. Int J Ther Rehabil 11(9): 425-34

I t has been proposed that a rehabilitative care approach may restore function in people with cancer as well as ameliorate perceptions of hopelessness and despair (Scialla et al, 2000). Frank et al (1998) also state that at any stage of life of the person with cancer, using a rehabilitative care approach could have benefits for symptom relief, psychological health and quality of life. Focusing on rehabilitation in palliative care would therefore enable health-care professionals to incorporate social, emotional and vocational issues, providing a holistic approach to the person with cancer and his or her family.

People with cancer encounter multiple symptoms that are complex and affect both the physical and the psychosocial aspects of their lives. The four main symptoms are pain, dyspnoea, nausea and fatigue, which are often distressing and difficult to manage (Curt, 2001). It is therefore important that rehabilitation in the context of palliative care is assessed to explore its effectiveness in managing these symptoms. In order to do this, it is essential that health-care professionals listen to people with cancer and learn from their experiences.

\section{REHABILITATIVE CARE APPROACH}

The rehabilitative care approach explored in this study aims to foster independence, self-respect and control, while providing relief from pain, dyspnoea, nausea and fatigue using the most appropriate research-based methods and symptom control available. The objective is to promote a partnership between the health-care professional and the person with cancer through a coordinated approach to treatment planning and goal setting, allowing the person's condition to be monitored effectively through detailed documentation. This is the cornerstone to the rehabilitative care approach philosophy (Higgs and Titchen, 1995)

Central to this philosophy is the redevelopment of the individual's optimal function in his or her current environment. This is achieved through multidisciplinary assessments, where each person with cancer is treated uniquely in response to his or her medical history, abilities, disabilities, environment and expectations, as well as his or her physical, intellectual, psychological and social make-up.

The person with cancer is given control and choice over his or her treatment input with guidance from the health-care professionals, which include the specialist palliative day care charge nurse and physiotherapist. Treatments include psychosocial support, lymphoedema management and transcutaneous electrical nerve stimulation (TENS) for pain control and nausea management.

\section{AIM OF RESEARCH}

The research aimed to explore patients' perceptions of the rehabilitative care approach at a specialist palliative day care centre and consider how the rehabili-
CA Belchamber is Senior I Oncology Physiotherapist, Poole Hospital NHS Trust, Poole, Dorset BH15 2JB, UK and MH Gousy is Principal Lecturer, University of Greenwich, School of Health and Social Care, London, UK

Correspondence to: CA Belchamber cbelchamber@o2.co.uk 
tative care approach may be improved. Research questions included the following:

What are people with cancers' perceptions of their symptoms?

How do people with cancer perceive the rehabilitation they received?

What attitudes or beliefs do people with cancer have about the rehabilitation they have received?

\section{LITERATURE REVIEW}

Research indicates that there is a higher prevalence of anxiety and depression in people with cancer compared to the normal population (Higginson, 1997), with Stone et al (2000) observing a strong correlation between fatigue and psychological distress. In addition, there is evidence that fatigue levels are positively linked with increased levels of pain (Blesch et al, 1991), dyspnoea (Brown et al, 1986), nausea (Knobf, 1986) and emotional upset (Nerenz et al, 1982).

Interestingly, Gadsby et al (1997) found that fatigue was improved eight-fold in people with cancer after using TENS, thus increasing quality of life. Symptoms were assessed using the European Organisation for the Research and Treatment of Cancer quality of life questionnaire (EORTC QLQ$\mathrm{C} 30$ ), which did not provide information on the effect of the treatment modalities on pain.

Mock et al (1997) investigated the effect of exercise on people with cancer and observed a significant reduction in fatigue levels in those who exercised $(n=22)$ compared with the control group who received usual care $(n=24)$. Syrjala et al (1995) compared four therapies: usual treatment; usual treatment with therapist support; usual treatment and relaxation/imagery training; and usual treatment and a package of cognitive behaviour coping skills plus relaxation/imagery. Participants reported less pain in the groups receiving the relaxation/imagery and the package of skills than those receiving the other interventions $(P<0.01)$. Fleming (1985) also investigated relaxation therapy in a hospice setting and indicated that $38 \%$ of the 58 people with advanced cancer pain had a reduction in their pain after relaxation therapy.

Spiegel et al (1981) showed that people with cancer who received group therapy had a statistically significant reduction $(P<0.01)$ in pain sensation, pain suffering and fatigue levels. Passik et al (1995) showed that women with upper limb lymphoedema who used 'avoidance coping mechanisms' experienced greater psychological morbidity, physical dysfunction, concerns relating to body image and pain than those women using active coping techniques.

Corner et al (1996) looked at the effect of the nonpharmacological approach for dyspnoea in lung can- cer, including breathing retraining, exercises, counselling, relaxation, teaching of coping and adaptation strategies. Results showed a median improvement in breathlessness at worst of $35 \%(P=0.02)$; an improvement in distress caused by breathlessness of $53 \%(P=0.02)$; and an improvement in functional capacity of $17 \%(P=0.03)$. Hately et al (2001) validated these results with significant improvements made in breathlessness at worst $(P<0.001)$, an improvement in distress caused by breathlessness $(P<0.001)$ and an improvement in functional capacity $(P<0.001)$. In addition, there was significant improvement in the participant's quality of life $(P=0.004)$ and $100 \%$ satisfaction with information, explanation and time given.

Diversional therapy was shown to be valuable to people with cancer in a study by Shaw and Wilkinson (1996), as it provided a sense of purpose - a factor thought to be essential for the overall wellbeing and self-identity of the person (Frampton, 1986). Participants also experienced 'transcendence', where they could remove themselves mentally from their illness. However, no well-designed studies on the efficacy of aromatherapy were found, with only one pertinent research paper identified in the management of nausea. This study used an N-of-1 design (Brown et al, 1992), where three treatment conditions were compared: acupressure wristband (at the commonly accepted P6 acupoint), placebo wristband and no band. Each treatment lasted approximately 4-8 hours. Results indicated no significant difference between the treatment conditions. However, McMillan and Dundee (1991) recommend using TENS on the Neiguan antiemetic acupuncture point.

Evidence from this literature search indicates that psychological distress is linked with fatigue, which emerges as the key symptom in people with cancer and has strong influences on levels of pain, nausea and dyspnoea. There are indications that group therapy, the non-pharmacological approach to breathlessness, exercise, relaxation and coping strategies all play a vital role in the management of these symptoms in isolation. This evidence was used to structure the rehabilitative care approach to explore its effectiveness in treating the person with cancer holistically. TENS, diversional therapy and aromatherapy were also included.

\section{METHOD}

Field et al (2001) recognize that research in palliative care should incorporate the physical, psychological and emotional components of the patient's experience. Qualitative research was therefore chosen as it has the ability to describe the form and nature of a particular phenomenon. As a result, it informs health-care professionals about illness and 
treatment in the context of everyday life, as well as investigates a previously unexplored topic or one that is inadequately recognized or not clearly defined (Britten et al, 1994).

Out of the five main qualitative methodologies, phenomenology was chosen to explore the rehabilitative care approach as it aims to uncover the essential structure of a phenomenon by exploring the 'outward appearance' and 'inward consciousness' rooted in the person's memory, image and meaning (Crombie, 1998). Phenomenology literally means 'the study of phenomena' and phenomenological research begins with the acknowledgement that there is a gap in our understanding (Wilson, 2000). Phenomenological-orientated psychological research was used, as it aims to answer two related questions:

What is the phenomenon that is experienced and lived?

How does it show itself?

These questions are answered by allowing participants to absorb and reflect upon their experiences in a variety of ways that are unique to them (Vale and King, 1978). This essential meaning should provide the researcher with the means to increase healthcare professionals' awareness and insight into the rehabilitative care approach at the specialist palliative day care centre.

\section{DATA COLLECTION}

For this qualitative study the researcher adopted the data collection cycle shown in Figure 1.

Semistructured interviews were used so that key issues could be explored in depth. The addition of an agenda meant that there was consistency to the raw data, providing a base for the initial stages of data analysis. Formulating questions around key issues (identified in the literature review) as well as focusing upon the aims and objectives of the research established the agenda. Open questions were sought and care was taken that they were not leading in any way. In addition to this, prompts were used to standardize the clarification process.

The layout of the agenda was organized with sensitivity, leaving the more probing and personal issues towards the end of the interview, so allowing time for rapport to be established and rich data to be extracted. A logical sequence of key issues enabled the participant to be at ease during the interview. The initial question was purposefully chosen to relate to the known reason for the research.

\section{Population characteristics}

Participant characteristics are presented in Table 1. Inclusional and exclusional criteria were incorporated (Table 2) to select a homogenous sample. Potential participants were required to be experienc- ing one of the four main symptoms of cancer - pain, dyspnoea, nausea or fatigue - in order to explore the effectiveness of the rehabilitative care approach on these symptoms. It was therefore necessary to eliminate people with cancer from the study who had other medical conditions, which would have had an effect on these symptoms.

Haemoglobin levels below $10 \mathrm{~g} / \mathrm{dl}$, where a blood transfusion and further palliative chemotherapy or

\begin{tabular}{|c|c|c|c|}
\hline \multicolumn{4}{|c|}{$\begin{array}{l}\text { TABLE } 1 . \\
\text { Participant characteristics }\end{array}$} \\
\hline \multirow[t]{2}{*}{ Demographics } & \multicolumn{2}{|l|}{ Age range } & $45-82$ years \\
\hline & \multicolumn{2}{|l|}{ Median age } & 66.1 years \\
\hline \multirow[t]{4}{*}{ Comorbidities } & \multirow{2}{*}{\multicolumn{2}{|c|}{$\begin{array}{l}\text { Patients referred fitting the inclusion/exclusion criteria } \\
\text { Patients referred who died before end of study }\end{array}$}} & $n=22$ \\
\hline & & & $n=7$ \\
\hline & \multirow{2}{*}{\multicolumn{2}{|c|}{$\begin{array}{l}\text { Patients referred who deteriorated before end of study } \\
\text { Patients referred who declined to take part }\end{array}$}} & $n=2$ \\
\hline & & & $n=5$ \\
\hline \multirow[t]{2}{*}{ Sex } & \multicolumn{2}{|c|}{ Males } & $n=3$ \\
\hline & \multicolumn{2}{|l|}{ Females } & $n=5$ \\
\hline \multirow{18}{*}{$\begin{array}{l}\text { General } \\
\text { characteristics }\end{array}$} & \multicolumn{2}{|c|}{ Live at home } & $n=8$ \\
\hline & \multicolumn{2}{|c|}{ Live in bungalow } & $n=2$ \\
\hline & \multicolumn{2}{|l|}{ Live in flat } & $n=1$ \\
\hline & \multicolumn{2}{|c|}{ Live in house } & $n=4$ \\
\hline & \multicolumn{2}{|c|}{ Live in residential home } & $n=0$ \\
\hline & \multicolumn{2}{|l|}{ Widowed } & $n=5$ \\
\hline & \multicolumn{2}{|c|}{ Married (two were second marriages) } & $n=3$ \\
\hline & \multicolumn{2}{|c|}{ Live alone } & $n=5$ \\
\hline & \multicolumn{2}{|c|}{ Live with wife and three daughters } & $n=1$ \\
\hline & \multicolumn{2}{|c|}{ Live with husband and son from previous marriage } & $n=1$ \\
\hline & \multicolumn{2}{|c|}{ Live with husband } & $n=1$ \\
\hline & \multicolumn{2}{|c|}{ Regular contact with family and friends } & $n=6$ \\
\hline & \multicolumn{2}{|c|}{ Found support from local church } & $n=2$ \\
\hline & \multicolumn{2}{|c|}{ Occasional contact from friends/family by phone } & $n=1$ \\
\hline & \multicolumn{2}{|c|}{ Working } & $n=0$ \\
\hline & Retired & & $n=6$ \\
\hline & Hoping to $r$ & work & $n=1$ \\
\hline & Housewife & & $n=1$ \\
\hline Current & Independen & le (no aids) & $n=6$ \\
\hline mobility & Independen & le with a stick & $n=1$ \\
\hline status & Independen & le with a rollator (delta frame) & $n=1$ \\
\hline Haemoglobin & Haemoglob & & $10.4-13.9 \mathrm{~g} / \mathrm{dl}$ \\
\hline Diagnosis & Primary: & Breast cancer & $n=3$ \\
\hline & & Unknown primary & $n=1$ \\
\hline & & Cancer of the oesophagus & $n=1$ \\
\hline & & Renal cell carcinoma & $n=1$ \\
\hline & & Cancer of the colon & $n=1$ \\
\hline & & Prostate cancer & $n=1$ \\
\hline & Secondary: & Bone & $n=2$ \\
\hline & & Liver & $n=3$ \\
\hline & & Lung & $n=4$ \\
\hline & & Lymph nodes & $n=2$ \\
\hline & & None & $n=1$ \\
\hline
\end{tabular}

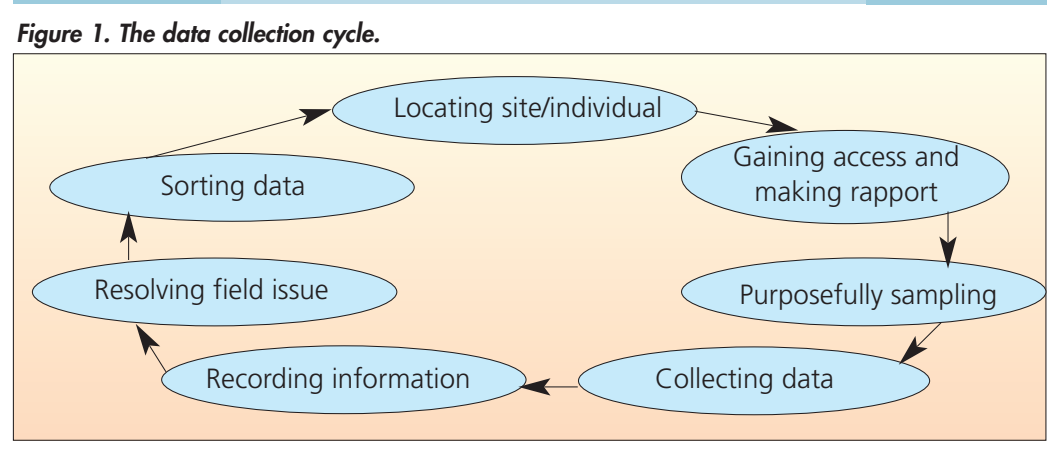


radiotherapy may be required, would have had an effect on the person's experience of fatigue. The participant also needed to be capable of understanding the study and what it involved, as well as cope with an interview that lasted 1 hour.

\section{Ethical issues}

Ethical approval was sought from the local ethics committee and access was obtained from the researcher's employer. One-to-one interviews were carried out to explain the research to the potential participant. During this interview, the person with cancer was asked whether he or she might volunteer to take part in the research. If the person volunteered, verbal consent was provided, protecting the rights of the research participant.

Following verbal consent, the researcher asked the participant for informed consent before the semistructured interview. On receipt of study information, each participant was asked to sign a consent form. Process consent (McLeod, 1996) was then used to gain consent at each stage. This process continued to protect the participant's vulnerability and the interviewer from any misunderstandings by the participant. Pseudonyms were also applied so that participants could not be identified and an identification code was issued on individual interview agenda forms. Confidentiality of the research environment was also protected.

\section{Data analysis}

Semistructured interviews were recorded and transcribed verbatim. Preconceived ideas about the phenomenon were isolated, enabling the researcher to comprehend the participant's views in depth.

Using a methodology developed by Colaizzi (1978), a series of steps were followed to analyse the raw data. This commenced with 'horizontalization', reducing the original transcriptions into significant statements, which were further condensed into formulated meanings. Words, statements and phrases were grouped according to their similarities and characteristics to produce key themes, forming the basis of the findings. These are categorized under the headings 'symptoms', 'quality of life', 'expectations', 'rehabilitation' and 'beliefs' (Tables 3.1-3.5).
From the collective formulated meanings, clusters of themes were arranged, signifying the emerging common themes. Making a reference back to the original descriptions and determining whether they remained true to the unique account validated the clusters of themes (Table 4). From this data analysis an exhaustive description of the phenomenon was compiled by amalgamating the results.

Description of the rehabilitative care approach During the rehabilitative care approach, the participant's perception of abandonment, anxiety and loss of control is altered through social contact, communication and group activities, as well as through the health-care professional's acknowledgement of the participant's individuality and through attentive listening and appropriate response. The participant's wellbeing is enhanced through a comforting, secure, stimulating and remedial environment, encouraging motivation and compliance.

Participants' perceptions of their physiological and psychological symptoms were transformed through the therapeutic interventions, which were described as 'subtle treatments that can be accessed as required'. The treatments helped to increase strength and reduce pain, fatigue and dyspnoea through opportunities and challenges - ultimately giving control back to the individual.

\section{RESULTS}

Nausea was not mentioned by the participants and so cannot be commented upon. However, symptoms of pain, dyspnoea and fatigue were all perceived as three-dimensional, consisting of physical, emotional and spiritual elements (Table 3.1). The combinations of psychosocial symptoms described had a direct correlation with the participants' perceptions of their physical symptoms and disabilities. The latter was demonstrated by the participants' description of their quality of life before the rehabilitative care approach, as seen in Table 3.2, where there was an overriding feeling of loss and isolation. This had a negative effect on their wellbeing, hope, self-esteem, role, social support, emotional support, energy, strength, mobility and control.

TABLE 2. 


\section{Pain}

Pain was described as terrifying, frightening and devastating. This emotional pain also had an effect on the participant's immediate family, social circle of friends and neighbours, often causing high levels of anxiety and feelings of isolation. Participants' experience of relaxation indicated that it had a positive effect on their perception of pain (Table 3.4), confirming Syrjala et al's (1995) research and adding corroboration to Fleming's (1985) research, that relaxation does help in pain relief in people with cancer. Group work was also perceived to reduce both physical and emotional pain (Table 3.4, Table 4), verifying Spiegel et al's (1981) research on group therapy.

\section{Dyspnoea}

Participants perceived that the non-pharmacological approach in the management of dyspnoea enabled them to control their breathlessness, which in turn improved their functional capacity and their overall quality of life (Table 3.4, Table 4). This supports and confirms both Corner et al's (1996) and Hately et al's (2001) research findings.

\section{Fatigue}

Before the rehabilitative care approach, participants found that fatigue had a direct impact on their quality of life, making activities of daily living virtually impossible and requiring will, effort and courage to carry them out (Table 3.1). Again, psychosocial factors contributed to the fatigue as well as loss of appetite, decreased weight, decreased strength from malnourishment and muscle atrophy.

This parallels with Gregory (2001), who states that collectively, fatigue in people with cancer has cognitive, psychological and physiological causes. Rhodes et al (1988) remark that this has a negative impact on the person's ability to carry out activities of daily living, which confirms the findings in Table 3.1. Further, it supports Stone et al's (2000) findings that that there is a correlation between fatigue and psychological distress and that there is a correlation between fatigue and levels of pain, dyspnoea and emotional upset. However, there was no correlation found between fatigue and nausea in this study.

Mock et al (1997) demonstrate that exercise reduces fatigue, which has been confirmed by this study, although the group setting was also an influential factor. Spiegel et al (1981) found that there was a significant reduction in fatigue in the intervention group who had attended weekly support meetings and so confirm the important role of group work in helping to reduce fatigue levels.

\section{Rehabilitation}

The rehabilitative care approach (Table 3.5) was perceived by participants as enhancing psychological feelings of wellbeing. This was achieved by providing the participants with time to explore their emotional needs, building trust between the professional and participant, which in turn produced an atmosphere of comfort and security. This care and attention was seen to have a positive psychological effect on the individual and was described as 'remedial.'

\section{Positiveness}

Participants perceived that their ability to do things increased through the 'positiveness' (Table 4) that had been generated during the rehabilitative care approach. Lifestyle changes, support from the different health-care professionals, talking, the removal of time constraints and the caring atmosphere were all contributory factors described by the participants as enabling them to accomplish more.
TABLE 3.2.

\section{Formulated meanings of significant statements - quality of life}

How would you describe your quality of life before receiving the care and now? Quality of Quality of life was poor because of low mood and negative attitude life before Negative thoughts led to low self-esteem and sense of abandonment Quality of life was reduced owing to physiological/psychological disabilities Quality of Mobility increased with an improvement in health and reduction in pain life after Reduced negative emotions increased ability to do more, alleviating fatigue Improved rapidly along with general condition, thus positively affecting the individual's whole life

Attending the specialist centre added to the individual's quality of life, enabling him to achieve more

Being in control of the situation provided individual with a sense of normality Improved through positive attitudes of 'happiness', 'fitness' and lack of worry 


\section{Environmental approach}

Overall, participants perceived that the rehabilitative care approach offered an environment in which they learned to develop personally within their illness. The factors that limited their effective functioning and behaviour were corrected, modified or adapted (Table 3.4), facilitating and maximizing their independence. The environment was also shown to dictate the individual's behaviour, which had an important impact on the lives of the people with cancer (Table 3.3). An environmental approach is therefore an essential element of the rehabilitative care approach.

\section{Normality and control}

Participants believed that the rehabilitative care approach improved their quality of life by giving them some sense and purpose (Table 3.5) and that it provided a reason to live instead of just 'existing'. They further stated that it was a source of diversion, enabling them to forget about their symptoms and providing an incentive to go out, which ultimately boosted their morale. This answers Burch et al's (1999) statement that:

'It would be useful to know whether activities involved in day centre attendance, such as getting ready, walking to transport and meeting other people, also lead to functional improvement.'

In addition, the rehabilitative care approach provided the participants with a sense of normality and control (Table 3.2). This feeling of control is perhaps the turning point in the rehabilitation process from isolation and depression to a sense of competence and self-esteem, which has been arrived at through the participant's own actions.

TABLE 3.3.

Formulated meanings of significant statements - expectations

What were your expectations of the specialist palliative day care centre? Expections before Lack of any expectation, with fear and uncertainty attending the Sense of abandonment, along with association of death palliative care centre: produced feelings of apprehension and reluctance to attend Courage required to face visions of 'silent' and 'moaning' people No expectation of improving their 'bodily health' Psychological feeling of wellbeing while attending Expections after Provided an incentive as well as comfort, through the ability attending the palliative care centre to express feelings during inquiry

Lack of time constraints provided a sense of security Contact with other people in similar situations was inspiring Psychological feeling of wellbeing remained after individual returned home, enabling an improved sleep pattern Meeting up with friends, chatting to the therapists and accomplishing something was important to the individual Sense of unity among the individuals was significant, learning from each others' experiences

Looking forward to the opportunity of attending Nice atmosphere and the pleasant company was found to be 'remedial' and therefore an enjoyment for the individual

The care and attention offered by the health professional had a positive psychological effect on the individual
Seligman (1975) suggests that self-esteem is built through the individual's perception that the quality of the experience was actually controlled by him or her and is therefore a protective mechanism against depression. Thus, it could be said that the rehabilitative care approach provides the psychological support necessary to reduce or minimize the physical and mental isolation found in people with cancer.

\section{DISCUSSION}

As a result of this study a number of issues have emerged, which may have important implications for the care of people with cancer.

\section{Normalization process}

A normalization process initiated the individual's rehabilitation and is defined as an acceptance of the diagnosis and disability and the particular needs of that individual with the disability. This process was promoted through environmental factors and diversional therapy. Once this normalization process had taken place, participants felt able to achieve more in their lives. Shaw and Wilkinson (1996) state:

'It is often said that people only feel

themselves to be truly alive when

stretching and testing themselves.'

Diversional therapy offered this to the participants as they frequently described their craft activities as challenging. This normalization process should therefore be seen as the foundation of all rehabilitation programmes and the key factor in judging the service's quality (O’Brien, 1980).

\section{Functional ability}

Functional ability was shown to improve with the rehabilitative care approach through a complex interlinking of therapies and environmental factors. In addition, there was some evidence that it helped to reduce fatigue. However, the experience of fatigue was often described as 'unexpected' and had an adverse affect on the person with cancer's functional ability. This parallels with Field et al's (2001) findings that functional ability in people with cancer suffering from fatigue was not a reliable way of assessing fatigue. A more holistic assessment tool is therefore required.

In general, there has been a preoccupation with the 'physicality' of rehabilitation and frequently the criterion for success has been related to whether the person with cancer is able to walk. Mulley (1994) believes this attitude to measuring rehabilitation is changing, but the process of moving away from the physical to the holistic approach is an extremely slow process. This may well be owing to the inherent difficulties in defining 'quality of life' (Brown et al, 1996). Providing a holistic assessment tool 
that can encompass the complexities of measuring the impact of rehabilitation in a palliative care setting would therefore be challenging.

\section{Ownership}

The transcriptions indicated that the health-care professionals at the specialist palliative day care centre were sensitive to people's feelings of isolation. During the rehabilitative care approach, each participant felt valued, accepted and respected as a person as their disability and needs were acknowledged. This promoted trust, enabling the professionals to search and discover the participant's unique and individual story. Mason (2000) says this is an essential skill required by health-care professionals as it encourages a sense of ownership within the rehabilitation programme.

Watson (1996) states that promoting a sense of ownership can be achieved through clinical reasoning. If successful, compliance can be attained along with self-responsibility and 'there may be psychological advantages in making people responsible for their treatment rather than victims of their pain' (McKinney, 1989). However, Ryan (1994) believes that a sense of ownership may in fact be more important than information in achieving compliance, whereas Cameron (1996) states that compliance can be enhanced through social support and that a lack of social support can contribute to non-compliance.

Therefore, for this concept of ownership to be successful, it is essential that health-care professionals and people with cancer are seen as equal and active partners so that careful documentation can be achieved, enabling appropriate referral to other health-care professionals while improving collaboration and multidisciplinary networking. This may also enhance the care pathway for people with cancer by ensuring collaboration across service boundaries.

\section{Outcome measures}

With recent government proposals there has been a renewed emphasis on outcome measures within the health-care services, which has become a focal point to assessing the effectiveness of service provision. Rehabilitation is already perceived within the medical profession as a predetermined process. However, Swift (1996) argues that there are very few universal indicators of outcome in rehabilitation. Evans et al (1995) carried out a meta-analysis of rehabilitation outcome measures and concluded that they are usually restricted to three main areas: survival, functional ability and discharge destination.

Renwick and Friefield (1996) comment that there is a need for theoretical underpinning in rehabilitation and challenge the simple empirical model available. Further, many of the existing measures not only use functional ability as an indicator for quality of life, but also are based on the health-care professional's perspective rather than the patient's perspective (Renwick and Friefield, 1996). The concept of rehabilitation for people with cancer is therefore of great value and this research has helped to provide that understanding. Fitzpatrick (1996) states that quality of life should represent the primary outcome of rehabilitation, which has been confirmed by this research (Table 3.2).

\begin{tabular}{|c|c|}
\hline \multicolumn{2}{|c|}{$\begin{array}{l}\text { TABLE 3.4. } \\
\text { Formulated meanings of significant statements - rehabilitation } \\
\text { How would you describe the care you have received at the palliative day care centre? }\end{array}$} \\
\hline General & $\begin{array}{l}\text { Rehabilitation was beneficial as there was always a health professional } \\
\text { available to address the problem } \\
\text { Caring atmosphere with the ability to talk and laugh was stimulating } \\
\text { The individuals felt 'very special' with the attention they received } \\
\text { Rehabilitation was 'good sensible practical advice' sought through } \\
\text { inquiry and discussion } \\
\text { Rehabilitation was accumulative, addressing the 'whole' person with } \\
\text { support from different health-care professionals } \\
\text { Psychologically, the health-care professionals were understanding, } \\
\text { providing support through a change of attitude such as 'positive thinking' } \\
\text { Through lifestyle changes, individuals were able to accomplish more } \\
\text { The importance of being together as a group was an overriding factor } \\
\text { in the rehabilitation of the person } \\
\text { Rehabilitation was concentrated into one day without any time constraint }\end{array}$ \\
\hline \multicolumn{2}{|c|}{ Has the care offered helped you to manage this area of your illness more successfully? } \\
\hline $\begin{array}{l}\text { Diversional } \\
\text { therapy }\end{array}$ & $\begin{array}{l}\text { Found it interesting and were inspired by other people's efforts } \\
\text { It provided opportunities of being creative, challenging them to achieve } \\
\text { and learn something new } \\
\text { Accomplishing the challenge provided individuals with a sense of worth } \\
\text { and ability to succeed in other areas of their rehabilitation }\end{array}$ \\
\hline $\begin{array}{l}\text { Group } \\
\text { exercises }\end{array}$ & $\begin{array}{l}\text { Found this a social event which they enjoyed, as it was in a group } \\
\text { The group setting acted as an incentive for all participating } \\
\text { Exercises were found to be beneficial, increasing mobility and strength } \\
\text { Exercises helped to replace sense of physical loss from the individual's past } \\
\text { Doing the exercises while sitting meant that whatever the individual's } \\
\text { physical disability, he/she was able to join in }\end{array}$ \\
\hline $\begin{array}{l}\text { Breathlessness } \\
\text { clinic } \\
\text { Aromatherapy }\end{array}$ & $\begin{array}{l}\text { Individual was more capable of controlling and dealing with breathlessness } \\
\text { Individual felt well enough informed to carry out the controlled breathing } \\
\text { Aromatherapy was relaxing, both physically and psychologically } \\
\text { Aromatherapy was soothing and helped with pain and cramp } \\
\text { An aromatherapy ointment was brilliant in resolving dry, split skin }\end{array}$ \\
\hline $\begin{array}{l}\text { Lymph- } \\
\text { oedema } \\
\text { clinic }\end{array}$ & $\begin{array}{l}\text { Compression stockings reduced oedema and pain and increased mobility } \\
\text { The support of the compression stockings was thought to have resolved } \\
\text { the paraesthesia and reduced the frequency of cramps } \\
\text { Having all the health-care professionals within the same building was } \\
\text { beneficial in speeding up the control of the symptom }\end{array}$ \\
\hline Education & $\begin{array}{l}\text { A need for information was met through the provision of a booklet } \\
\text { Being able to refer to the booklet for information was an enormous help } \\
\text { Having information written down about the prescribed medication } \\
\text { enabled the individual to recognize and understand what the tablets } \\
\text { were for, which was thought to be beneficial }\end{array}$ \\
\hline Spiritual & $\begin{array}{l}\text { Having a strong faith was helpful in coping with the cancer } \\
\text { Support was given through prayer as well as attending the church, } \\
\text { providing spiritual support along with the physiological and } \\
\text { psychological support }\end{array}$ \\
\hline $\begin{array}{r}\text { How would } \\
\text { the }\end{array}$ & $\begin{array}{l}\text { Oou describe the communication between the health-care professionals at } \\
\text { ntre and the other health-care professionals you are involved with? }\end{array}$ \\
\hline $\begin{array}{l}\text { Health-care } \\
\text { professionals }\end{array}$ & $\begin{array}{l}\text { Communication was excellent; more time to talk/listen without distractions } \\
\text { Collaboration linked the centre with the local hospital and doctor } \\
\text { Health professionals were professional; networking was accurate and timely } \\
\text { All health-care professionals were helpful, referring individuals appropriately }\end{array}$ \\
\hline
\end{tabular}




\section{CONCLUSION}

Not all symptoms experienced by people with cancer reside totally in the pathology or are directly

TABLE 3.5 .

Formulated meanings of significant statements - beliefs

Describe what you feel has benefited you by attending the specialist day centre

Rehabilitative care provided is a form of 'treatment'

Physiotherapy is a treatment, but also 'social' in the context of exercise classes Rehabilitative care has more of a subtle nature than that received in hospital Rehabilitative care changed people's thought patterns, enabling them to become more aware of what they were able to achieve

The rehabilitative care approach helps distract the individual from his/her symptoms, both physically and psychologically

The ability to choose to participate in some of the rehabilitative care provided a sense of freedom, allowing the individual to achieve more in his or her own time Rehabilitative care provided a reason to llve, instead of just existing Rehabilitative care is a 'diversion', making you forget about symptoms, removing worries while providing you with an incentive to go out, which boosts morale The distraction is carried over to everyday life as individuals become preoccupied with the choice of care available to them - of great benefit to isolated individuals Rehabilitative care improved people's quality of life, giving it some sense and purpose Individuals didn't realise there was the opportunity to have rehabilitative care, which improved their wellbeing

Seeing other people coping with cancer changed their perception of their own symptoms and how they were coping

Describe what improvements you would make to the care you have received

A desire to come more frequently and participate in more of the care provided A lack of time to do all that they wished to achieve on the day they attended Individuals should be called guests, not patients - they were being treated as a person and accepted as a unique individual attributed to the disability itself. This is in contrast to the clinical perspective of rehabilitation, where there is an assumption that the symptoms of people with cancer exist solely in their pathology, disability and limitations rather than in a sense of devalued status (Galvin, 1983). The rehabilitative care approach was sensitive to this and has, therefore, managed the symptoms experienced by people with cancer effectively. However, it requires resources, willingness and enthusiasm to deliver this extended care (Hopkins and Tookman, 2000).

\section{Further research}

Further investigation is required into diversional therapy, which was seen to play an important role in the management of dyspnoea, fatigue and the normalization process of the person with cancer. Diversional therapy was also seen as an incentive for the individual's functional ability.

- Aromatherapy showed promise in reducing physical, emotional and spiritual pain as well as improving cramp, and demonstrated its healing effect on skin damaged through chemotherapy. Again, this warrants further investigation.

- The management of lymphoedema also reduces the frequency of cramps and paraesthesia, which requires further investigation.

- Contraindications and effects of TENS on reducing physical pain in people with cancer, as well as fatigue and nausea, needs to be investigated. The researcher was unable to obtain any data on this subject in the sample group studied.

\section{TABLE 4.}

Clusters of common themes

$\begin{array}{lll}\text { 1. Participants' } & \text { a. Negative feelings and attitudes arose from isolation, producing a sense of abandonment }\end{array}$

negativeness b. The sense of abandonment increased anxiety and stress levels, ultimately leading to loss of control

2. Participants' $\quad$ a. Positive feelings/attitudes were nurtured through contact with peers and health professionals, producing a sense of unity

positiveness b. The sense of unity was increased through group activities, communication, enquiry and the ability to express emotions, producing a feeling of wholeness

3. Participants' a. The health-care professionals acknowledge participants' individuality through attentive listening and responding individuality to them as valued individuals

b. The health-care professionals treated them as valued professionals

4. Environment's a. Participants perceived the atmosphere as being comforting, secure, stimulating and remedial, providing a sense of wellbeing atmosphere $b$. The sense of wellbeing increased motivation and compliance and a produced positive change in how the participant perceived his/her symptoms

5. Physiological a. Pain was associated with cramp, lymphoedema, parathesia and disturbed sleeping patterns

symptoms b. Aromatherapy and compression stockings helped reduce these symptoms with a resultant improvement in mobility

c. Dyspnoea was difficult to cope with and distressing

d. The breathlessness clinic enabled them to control and deal with this symptom more effectively, while the diversional therapy helped to take their mind off the dyspnoea

e. Fatigue was totally draining, causing weakness and heaviness with loss of appetite, weight, stamina, motivation and control, leading to difficulties in carrying out activities of daily living

f. Group exercises were an incentive and helped to increase strength, while diversional therapy provided an opportunity to accomplish something, which increased self-esteem and the ability to succeed in other areas of their rehabilitation

6. Therapeutic a. Therapeutic interventions had a direct effect on participants' perception of their physiological and psychological wellbeing interventions b. Participants perceived an overall positive effect on their body health, with an increase in strength and reduction in pain, fatigue and dyspnoea

7. Rehabilitative a. Participants perceived this as 'subtle treatments that could be accessed when required', with an overall accumulative care supportive effect

b. Treatments opened up opportunities, challenges and the ability to accomplish tasks; therefore provided a sense of control 
Research is needed into devising a universal holistic assessment tool and outcome measure for rehabilitation in palliative care. IJTR

Conflict of interest: none.

Blesch KS, Paice JA, Wickham R et al (1991) Correlates of fatigue in people with breast or lung cancer. J Pain Symptom Manage 4: 59-63

Britten N, Jones R, Murphy E, Stacy R (1994) Association of University Departments of General Practice: Qualitative Research Methods in General Practice and Primary Care. National Institutes of Health: Office of Behavioural and Social Sciences Research, Maryland

Brown ML, Carrieri V, Janson-Bjerkle S, Dodd MJ (1986) Lung cancer and dyspnoea: the patient's perception. Oncol Nurs Forum 13: 519-24

Brown S, North D, Marvel MK, Fons R (1992) Acupressure wristbands to relieve nausea and vomiting in hospice patients: do they work? Am J Hosp Palliat Care 9: 26-9

Brown I, Renwick R, Nagler M (1996) The centrality of quality of life in health promotion and rehabilitation. In: Renwick R, Brown I, Nagler M. Quality of Life in Health Promotion and Rehabilitation: Conceptual Approaches Issues and Applications. Sage Publications, California

Burch S, Longbottom J, McKay M, Borland C, Prevost T (1999) A randomised controlled trial of day hospital and day centre therapy. Clin Rehabil 13: 105-12

Cameron C (1996) Patient compliance: recognition of factors involved and suggestions for promoting compliance with therapeutic regimes. J Adv Nurs 24: $244-50$

Colaizzi PF (1978) Psychological research as the phenomenologist views. In: Vale R, King M. Existential Phenomenological Alternatives for Psychology. Oxford University Press, New York: 48-71

Corner J, Plant H, A’Hern R, Bailey C (1996) Non-pharmacological intervention for breathlessness in lung cancer. Palliat Med 10: $299-305$

Creswell JS (1998) Qualititative Injury and Research Design: Choosing Among the Five Traditions. 1st edn. Sage Publications, California

Crombie IK (1998) Research in Health Care: Design, Conduct and Interpretation of Health Services Research. 3rd edn. Joh Wiley and Sons, Chichester

Curt GA (2001) Fatigue in cancer-like pain, this is a symptom that physicians can and should manage. Br Med J 322: 1560

Evans RL, Connis RT, Hendrick RD, Haselkem JK (1995) Multidisciplinary rehabilitation vs medical care: a meta-analysis. Soc Sci Med 40: 1699-706

Field D, Clark D, Corner J, Davis C (2001) Facing Death Researching Palliative Care. 1st edn. Open University Press, Philadelphia

Fitzpatrick R (1996) Patient centred approaches to the evaluation of health care. In: Fulford KWM, Ersser S, Hope T. Essential Practice in Patient-centred Care. Blackwell Science, Oxford: Practice
$229-40$

Fleming U (1985) Relaxation therapy for far-advanced cancer Practitioner 299: 471-5

Frampton D (1986) Restoring creativity to the dying patient. $\mathrm{Br}$ Med J 293(6562): 1593-5

Frank C, Hobbs NR, Stewart GI (1998) Rehabilitation on pallitaive care units: case discussion. J Palliat Care 14 (2) $50-3$

Gadsby JG, Franks A, Jarvis P et al (1997) Acupuncture-like transcutaneous electrical nerve stimulation within palliative care: a pilot study. Complement Ther Med 5: 13-18

Galvin D (1983) The clinical attitude in rehabilitation and alternatives a reaction. In: Woods D, Wolf A, Brubaker D. The Clinical Model in Rehabilitation and Alternatives. World Rehabilitation Fund, New York

Gregory AC (2001) Fatigue in cancer. Br Med J 322: 1560

Hately J, Scott A, Laurence V, Baker R, Thomas P (2001) A Palliative-care Approach for Breathlessness in Cancer: A Clinical Evaluation. Help the Hospices, London

Higginson I (1997) Palliative Care and Terminal Care: Health Care Needs Assessment. Radcliffe Medical Press, Abingdon

Higgs J, Titchen A (1995) The nature, generation and verification of knowledge. Physiotherapy 81(9): 521-30

Hopkins K, Tookman A (2000) Rehabilitation and specialist palliative care - recent developments affecting the provision of rehabilitative care. Int J Palliat Nurs 6(3): 123-30

Knobf MT (1986) Physical and psychological distress associated with adjuvant chemotherapy in women with breast cancer. Clin Oncol 4(5): 678-84
Mason W (2000) Exploring rehabilitation within lymphoedema management. Int J Palliat Nurs 6(6): 265-73

McKinney LA (1989) Early mobilisation and outcome in acute sprains of the neck. Br Med J 299: 1006-8

McLeod J (1996) Qualitative approaches to research in counselling and psychotherapy: issues and challenges. Br J Guid Counc 24(3): 309-16

McMillan CM, Dundee JW (1991) The role of transcutaneous electrical stimulation of Neiguan anti-emetic acupuncture point in controlling sickness after cancer chemotherapy. in controlling sickness

Mock V, Dow KH, Meares CJ et al (1997) Effects of exercise on fatigue, physical functioning and emotional distress during radiation therapy for breast cancer. Oncol Nurs Forum 24(6): 991-1000

Mulley GP (1994) Principles of rehabilitation reviews. Clin Gerontol 4: 16-19

Nerenz DR, Leventhal H, Love RR (1982) Factors contributing to emotional distress during cancer chemotherapy. Cancer 50(5): $1020-7$

O'Brien J (1980) The Principle of Normalisation: A Foundation for Effective Services. Responsive Systems Associates, Atlanta

Passik S, Newman M, Brennan M, Tunkel R (1995) Predictors of psychological distress, sexual dysfunction and physical functioning among women with upper extremity lymphoedema related to breast cancer. Psycho Oncology 4: 255-63

Renwick R, Friefield S (1996) Quality of life and rehabilitation. In: Renwick R, Brown I, Nagler M. Quality of Life in Health Promotion and Rehabilitation: Conceptual Approaches, Issues and Applications. Sage Publications, California: 26-38

Rhodes VA, Watson PM, Hanson BM (1988) Patients' descriptions of the influence of tiredness and weakness on self-care abilities. Cancer Nurs 11(3): 186-94

Ryan T (1994) Interpretations of illness and non-compliance with nursing care. BrJ Nurs 3(4): 163-7

Scialla S, Cole R, Scialla T, Bednarz L, Scheerer J (2000) Rehabilitation for elderly patients with cancer asthenia: making a transition to palliative care. Palliat Med 14: 121-7

Seligman ME (1975) Helplessness on Depression, Development and Death. WH Freeman, New York

Shaw R, Wilkinson S (1996) Building pyramids: palliative care patients' perceptions of making art. Ther Rehabil 2(4): 217-21

Spiegel D, Bloom J, Yalom I (1981) Group support for patient with metastatic cancer - a randomised prospective outcome study. Arch Gen Psychiatry 38: 527-33

Stone P, Richards M, A'Hern R, Hardy J (2000) A study to investigate the prevalence, severity and correlates of fatigue among patients with cancer in comparison with a control group of volunteers without cancer. Ann Oncol 11: 561-7

Swift GG (1996) Disease and disability in older people: prospects for intervention. In: Squires AJ. Rehabilitation of Older People - a Handbook for the MDT. Chapman Hall, London: 12-26

Syrjala KI, Donaldson GW, Davis MW et al (1995) Relaxation and imagery and cognitive-behavioural training reduce pain during cancer treatment: a controlled clinical trial. Pain 63: 189-98

Vale R, King M (1978) Existential phenomenological alternatives for psychology. Oxford University Press, New York

Watson G (1996) Neuromusculoskeletal physiotherapy: encouraging self-management. Physiotherapy 82(6): 352-7

Wilson A (2000) Research Approaches in Primary Care: Primary Care Research Series. Radcliffe Medical Press, Abingdon

\section{KEY POINTS}

- This study provides an insight into patients' perspectives of a rehabilitative care approach at a specialist palliative day care centre.

- Patients' perspectives of their symptoms, beliefs and attitudes towards the approach are explored.

- This provides the researcher with the means to increase health-care professionals' awareness and insight into the rehabilitative care approach.

Common themes were seen to have a positive outcome on the general wellbeing of people with cancer.

- A list of further research for improving rehabilitative care for people with cancer is provided. 


\section{Clinical}

\section{COMMENTARY}

The recently published National Institute for Clinical Excellence (NICE) (2004) guidance on cancer services, Improving Supportive and Palliative Care for Adults with Cancer, sets out clear recommendations. It states that people affected by cancer should have access to a wide spectrum of services which will address physical, emotional, spiritual and social needs and improve their quality of life, and that they should be involved in the decision making about their care.

Belchamber and Gousy's article investigates the importance of rehabilitation in a palliative day care setting and raises many issues pertinent to the NICE guidance. By exploring the patients' perspectives, they are indeed endeavouring to be client-centred. Further, the authors illustrate the many similarities between the ethos of rehabilitation and palliative care - that they are client-centred, symptomfocused and aim for improved quality of life.

They ably recognize the complex interplay of symptoms and how these symptoms affect a person on a physical, emotional and spiritual level. They particularly, and justifiably, acknowledge fatigue as a debilitating impact of cancer and its treatments. As illustrated here, the mind-set of rehabilitation being purely a 'physical' discipline is being replaced by recognition that there are many varied non-pharmalogical interventions with which to meet an individual's multifaceted needs.

The article charts the shift from a patient's sense of loss and isolation through adjustment to achieving improved quality of life with rehabilitation as the catalyst. Other integral factors having a positive effect seem to be the caring environment, support from health-care professionals, talking and patient control and 'ownership' of their care.

The range of rehabilitative media discussed and the professionals involved are by no means exhaustive. The Fulfilling Lives document (National Council for Hospice and Specialist Palliative Care Services, 2000) and the NICE (2004) guidance include descriptions of the recommended components of a multiprofessional team.

As an occupational therapist, I was disappointed to see the omission of an occupational therapist in the team described in this article. Occupational therapists are able to contribute a breadth of interventions including management of anxiety, breathlessness and lifestyle issues, as well as assessment of activities of daily living and of the home environment.

However, the authors have provided an important insight into the patient's perspective and have demonstrated how vital rehabilitation in palliative care is in improving an individual's quality of life as championed in the Fulfilling Lives document. They have challenged us as professionals to value the person with cancer, listen to his or her own 'unique and individual story' and tailor rehabilitation accordingly.

\section{Helen Barrett}

Senior Occupational Therapist

The Royal Marsden NHS Trust Sutton

Surrey SM2 5PT

UK

National Council for Hospice and Specialist Palliative Care Services (2000) Fulfilling Lives: Rehabilitation in Palliative Care. National Council for Hospice and Specialist Palliative Care Services, London

National Institute for Clinical Excellence (2004) Guidance on Cancer Services: Improving Supportive and Palliative Care for Adults with Cancer. National Institute for Clinical Excellence, London
International Journal of Therapy and Rehabilitation

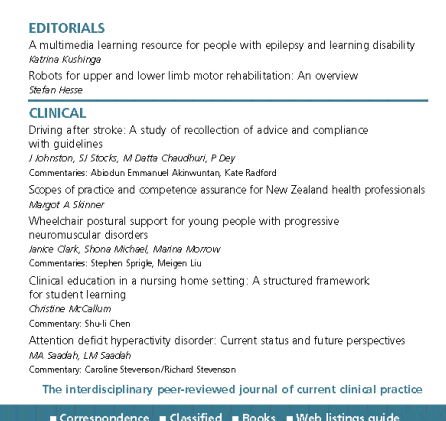

\section{Write for us}

IJTR is always keen to encourage a wide, interdisciplinary range of authors. If you have undertaken some research or audit and feel that you should make others aware of the findings, then why not write an article for IJTR and let everyone know what you have found.

To obtain a copy of instructions to authors, or for any queries you may have, contact Caroline Finucane on $+44(0) 2075016713$ or e-mail her at caroline@markallengroup.com 